\title{
Factors Affecting Chinese Hamster Ovary Cell Proliferation and Viability
}

\author{
Alina Rekena \\ Rudolfs Cimdins Riga Biomaterials \\ Innovations and Development \\ Centre, Insitute of General Chemical \\ Engineering, Faculty of Materials \\ Science and Applied Chemistry \\ Riga Technical University \\ Riga, Latvia \\ alina.rekena@rtu.lv
}

\author{
Dora Livkisa \\ Department of Microbiology and \\ Biotechnology, Faculty of Biology \\ University of Latvia \\ Riga, Latvia \\ dora.livkisa@lu.lv
}

\author{
Dagnija Loca \\ Rudolfs Cimdins Riga Biomaterials \\ Innovations and Development Centre, \\ Insitute of General Chemical Engineer- \\ ing, Faculty of Materials Science and \\ Applied Chemistry \\ Riga Technical University \\ Riga, Latvia \\ dagnija.loca@rtu.lv
}

\begin{abstract}
Advantageous cultivation procedures for the Chinese hamster ovary (CHO) cells are necessary for the productive commercial production of biopharmaceuticals. A main challenge that needs to be addressed during the process development is the differences in each cell line requirements concerning the nutrients and feed strategies in order to achieve the desired growth characteristics. Therefore, within the current research, a naïve high cell density serum free suspension adapted CHO cell line was tested with glucose and glutamine rich feeds in fed-batch Erlenmeyer shake flask cultures. Glucose consumption rate was adjusted to develop the optimal feed strategies. Obtained results indicated that high glucose and L-glutamine feeding did not improve maximum viable cell density compared to the control samples. During the exponential phase, cell proliferation and viability of all feeds showed no statistically significant difference. Instead, the fed-batch processes tested led to statistically significant differences in viable cell density and cell viability during the decline phase, compared to control (batch) culture. The difference between glucose and glutamine feeding was indistinguishable, most probably due to the concentration imbalance with the rest of the nutrients in feed. The overall study presented a method to slow down the decrease in $\mathrm{CHO}$ cell proliferation and viability during the decline phase, instead of increasing the maximum cell density at the plateau phase.
\end{abstract}

Keywords-biotechnology, cell proliferation, Chinese hamster ovary cells, feeding strategy.

\section{INTRODUCTION}

Chinese hamster ovary (CHO) cells are widely used for biopharmaceutical production. Production of recombinant cytokines, fusion proteins, monoclonal antibodies and others requires specific nutrient components to support cell growth in vitro [1]. Therefore, nutrient composition in culture media and the manner of media supply during the cultivation process have been extensively studied.

The main energy sources in chemically defined $\mathrm{CHO}$ cell culture media are carbohydrates (glucose, primarily) and glutamine [2]. Supplementation of glutamine in cell media can help to maintain higher cell viability profile and reduce lactate generation [3]. In the absence of glutamine, cells have a delayed start of exponential phase [4]. On the other hand, as a result of cell metabolism and the so-called glucoglutaminolysis, potential inhibitory byproducts are generated [5]. High glucose concentration can lead also to lactate accumulation which can further affect the cell growth [6], therefore, glucose concentration limits have been extensively studied [7]. High glutamine supplementation, however, can lead to ammonium accumulation which significantly inhibits the cell growth [8]. In this regard, maximum permittable ammonium concentrations should be seriously considered during the experimental procedures. Also, an interaction between consumption rates of glucose and glutamine has been investigated. For example, glucose consumption can be influenced by the glutamine excess [9]. Substitutions for both glucose and glutamine as the energy sources in the media have been proven to be effective [2].

Cell cultivation can be organized in either a batch or a fed-batch process. Fed-batch process means that after supply of basal medium at the beginning of fermentation, cells are later on supplemented with a feed medium which, in its simplest form, supplies only glucose in the range of 1.0-10.0 mmol/L [10]. Feed media usually contain 10-15 times higher nutrient concentrations than in the basal medium [10]. In order to optimize the process, both appropriate feed medium design and the experimental approaches have to be selected. While the stoichiometric model serves for the measuring of nutrient demand rates, the metabolic flux analysis provides an opportunity to understand metabolic pathways in-depth [11][12].

During present research, $\mathrm{CHO}$ cell cultivation process development using controlled glucose consumption rate in a fed-batch regime was carried out in order to test the effect of glucose rich and L-glutamine rich feed media on $\mathrm{CHO}$ cell proliferation and viability.

\section{MATERIALS AND METHODS}

\section{A. Materials used}

A naïve Chinese hamster ovary cell line FreeStyle ${ }^{\mathrm{TM}}$

Print ISSN 1691-5402

Online ISSN 2256-070X

http://dx.doi.org/10.17770/etr2019vol1.4106 C 2019 Alina Rekena, Dora Livkisa, Dagnija Loca. Published by Rezekne Academy of Technologies. 
CHO-S adapted to high maximum cell density, serum-free suspension culture from Thermo Fisher Scientific (Carlsbad, USA). Cell culture basal medium FreeStyle ${ }^{\mathrm{TM}} \mathrm{CHO}$ Expression Medium (Life Technologies, New York, USA). Media supplements: L-glutamine (200 mM) (Gibco®, Life Technologies, Paisley, UK), PenStrep antibiotics (Gibco ${ }^{\circledR}$, Life Technologies, New York, USA), glucose powder (Cargill, Krefeld, Germany). Other reagents: phosphate buffer (hereinafter, PBS) without $\mathrm{Ca}^{2+}$ and $\mathrm{Mg}^{2+}$ (Dulbecco's PBS, Gibco ${ }^{\circledR}$, Life Technologies, Paisley, UK), trypan blue stain (Life Technologies, New York, United States). Materials: $125 \mathrm{~mL}$ Erlenmeyer cell culture shake flasks (Corning®, Merck, New York, USA) with $40 \mathrm{~mL}$ initial basal media working volume, $0.2 \mu \mathrm{m}$ membrane filters (LLG®, Meckenheim, Germany). Equipment and devices: $\mathrm{CO}_{2}$ incubator (New Brunswick ${ }^{\mathrm{TM}} \mathrm{S} 41 \mathrm{i}$, Eppendorf, Hamburg, Germany), hemocytometer (Neubauer Improved Assistent ${ }^{\circledR}$, Hecht-Assistent, Sondheim/ Rhn, Germany), glucose meter Accu-Check ${ }^{\circledR}$ Active (Roche Diagnostics, Mannheim, Germany).

\section{B. Methods for the preparation of cell media}

Cell culture basal medium was prepared by supplementing FreeStyle ${ }^{\mathrm{TM}} \mathrm{CHO}$ Expression Medium with $8 \mathrm{mM}$ L-glutamine and 1\% (v/v) antibiotics. Apart from glucose, there are inorganic salts containing magnesium, calcium, potassium, sodium, phosphate, chloride, sulfate, bicarbonate ions, trace elements, approximately 20 different amino acids, approximately 10 different vitamins, and several growth factors contained in the basal medium [2].

In combination with basal medium, three feed systems and the control were compared being: 1) basal medium with increased glucose concentration (hereinafter, Glucose Feed); 2) basal medium with increased glucose concentration (hereinafter, Glutamine Control); 3) basal medium with increased glucose and L-glutamine concentration (hereinafter, Glutamine Feed); and 4) basal medium with phosphate buffer solution (hereinafter, Control Feed).

Glucose Feed consisted of $4 \mathrm{~mL} /$ day basal medium supplemented with glucose powder. The target levels of glucose concentration are listed on Table I. Firstly, the amount of glucose $m_{n}(g)$ in one flask is calculated according to equation 1 :

$$
m_{n}=C_{n} \times V_{n} \times 180.156 \times 10^{-6}
$$

where $\mathrm{Cn}(\mathrm{mmol} / \mathrm{L})$ is glucose concentration as measured, $\mathrm{Vn}(\mathrm{mL})$ is the cell culture volume before feeding and 180.156 is the molar mass of glucose.

The amount of glucose mbasal (g) in the basal medium is calculated according to equation 2 :

$$
m_{\text {basal }}=C_{\text {basal }} \times V_{\text {feed }} \times 180.156 \times 10^{-6}
$$

where $\mathrm{C}_{\text {basal }}(\mathrm{mmol} / \mathrm{L})$ is glucose concentration in basal medium used for the preparation of feed media (Table II) and $\mathrm{V}_{\text {feed }}(4 \mathrm{~mL})$ is the total volume of the feed. Finally, the total amount of glucose $\mathrm{m}(\mathrm{g})$ to be added in the Glucose Feed medium is calculated according to equation 3 :

$$
m=m_{n+1}-m_{n}-m_{\text {basal }}
$$

Glutamine Control (4 mL/day) consisted of basal medium, PBS solution and glucose powder. The total amount of PBS to be added is calculated according to equation 4 (see below), and the volumes used are listed on Table III. The target levels of glucose concentration for this feed are listed on Table I. The total amount of glucose to be added is calculated according to equations 1-3 and 5 .

Glutamine Feed (4 mL/day) consisted of basal medium, L-glutamine solution and glucose powder. The target level of glutamine concentration was set to 4 $\mathrm{mmol} / \mathrm{L}$ during the whole feed schedule. It was set on 4 $\mathrm{mmol} / \mathrm{L}$ or one half of what is recommended for the initial basal medium, respectively. The amount of L-glutamine $(\mathrm{mL})$ to be added is calculated according to equation 4 :

$$
V_{G L N}=\frac{4 \times\left(V_{n}+4\right)}{C_{G L N}}
$$

where $\mathrm{C}_{\mathrm{GLN}}(200 \mathrm{mmol} / \mathrm{L})$ is the concentration of glutamine based on supplier's information. Volumes of L-glutamine used are listed in Table III.

Glutamine Feed was supplemented with glucose as glutamine cannot support the cell growth in case of its absence [13]. The target levels of glucose concentration for this feed are listed on Table I. The total amount of glucose to be added is calculated according to equations $1-3$, except that in case of L-glutamine addition to the feed, Eq. 2 has to be modified in respect to $\mathrm{V}_{\mathrm{GLN}}$ according to equation 5 :

$$
V_{\text {feed(GLN) }}=V_{\text {feed }}-V_{G L N}
$$

Control Feed (4 mL/day) consisted of PBS only.

TABLE I.

\begin{tabular}{|l|c|c|c|c|}
\hline \multirow{2}{*}{ Type of feed } & \multicolumn{4}{|c|}{ Target level of glucose concentration (mmol/L) } \\
\cline { 2 - 5 } & Feed day 1 & Feed day 2 & Feed day 3 & Feed day 4 \\
\hline $\begin{array}{l}\text { Glucose } \\
\text { Feed }\end{array}$ & 18 & 18 & 26 & 26 \\
\hline $\begin{array}{l}\text { Glutamine } \\
\text { Control/ } \\
\text { Glutamine } \\
\text { Feed }\end{array}$ & 16 & 16 & 16 & 16 \\
\hline
\end{tabular}

TABLE II.

\begin{tabular}{|l|c|c|c|c|}
\hline \multirow{2}{*}{ Type of feed } & \multicolumn{4}{|c|}{$\begin{array}{c}\text { Glucose concentration of basal medium** } \\
\text { (mmol/L) }\end{array}$} \\
\cline { 2 - 5 } & Feed day 1 & Feed day 2 & Feed day 3 & Feed day 4 \\
\hline $\begin{array}{l}\text { Glucose } \\
\text { Feed }\end{array}$ & 26 & 26 & 26 & 26 \\
\hline $\begin{array}{l}\text { Glutamine } \\
\text { Control/ } \\
\text { Glutamine } \\
\text { Feed }\end{array}$ & 31 & 31 & 32 & 32 \\
\hline
\end{tabular}

** Although prepared according to the same supplier's protocols, different glucose concentrations were measured among batches of basal medium. 
TABLE III

\begin{tabular}{|l|c|c|c|c|}
\hline \multirow{2}{*}{ Type of feed } & \multicolumn{4}{|c|}{ Volume of L-glutamine or PBS (mL) } \\
\cline { 2 - 5 } & Feed day 1 & Feed day 2 & Feed day 3 & Feed day 4 \\
\hline $\begin{array}{l}\text { Glutamine } \\
\text { Control/ } \\
\text { Glutamine } \\
\text { Feed }\end{array}$ & 0.88 & 0.96 & 1.04 & 1.12 \\
\hline
\end{tabular}

\section{Fed-batch cultures}

Prior inoculation of the fed-batch cultures purchased Chinese hamster ovary cells were thawed, sub cultured in basal medium every 2-3 days (duration of one passage) in the lag phase at $0.2 \times 10^{6}$ viable cells $/ \mathrm{mL}$ and cryopreserved in a cell bank. Then cell passages 22 and 29 were taken from the cell bank, thawed and inoculated in disposable $125 \mathrm{~mL}$ Erlenmeyer cell culture shake flasks with $40 \mathrm{~mL}$ initial basal media working volume in triplicate at $0.2 \times 10^{6}$ viable cells $/ \mathrm{mL}$. Cells were cultivated in $\mathrm{CO}_{2}$ incubator with shaking speed $125 \mathrm{rpm}$ ( $25 \mathrm{~mm}$ orbital shaking diameter) at $8 \% \mathrm{CO}_{2}, 37^{\circ} \mathrm{C}$ and $95 \%$ humidity.

Feed addition was started when cells reached plateau phase for all tested conditions with a daily bolus addition $(4 \mathrm{~mL})$ of four different feed media as described in section "Methods for the preparation of cell media". Plateau phase was defined when the average cell density did not increase within the standard deviation range for one consecutive day. The measurement of average glucose concentration at the day before plateau then was taken as the target glucose level (see Table I). Feed supply was restricted to $40 \%$ of initial working volume. Accordingly, there were four feed additions in the volume of $4 \mathrm{~mL}$ each. Before adding to the cell cultures, feed was filtered through 0.2 $\mu \mathrm{m}$ membrane filter. Cell cultures were terminated when the average viability of triplicates dropped below $60 \%$.

\section{Cell density and viability measurements}

Daily sampling started from day 1 of cultivation for every cultivation experiment. In sterile conditions, $10 \mu \mathrm{L}$ sample was taken directly from each cell culture flask and mixed with $10 \mu \mathrm{L}$ trypan blue stain for a manual determination of total and viable cell density by the trypan blue exclusion method using a hemocytometer. Briefly, cells in hemocytometer chamber were counted under the microscope and sorted into viable (white colour) and dead (blue colour) cells. Glucose concentrations were daily measured using glucose meter. Glucose consumption $(\mathrm{g} / \mathrm{L})$ is calculated according to equation 6 :

$$
G C_{n}=\left(C_{n-1}-C_{n}\right) \times 180.156 \times 10_{-3}
$$

\section{E. Statistical evaluation}

All results were expressed as the mean value \pm standard deviation (SD) of three independent samples. The significance of the results was evaluated using unpaired Student's tests with the significance set at $p>0.05$. One way analysis of variance (ANOVA) was performed to evaluate the difference between the results.

\section{RESULTS AND DISCUSSION}

In this study, the method of media supply during the cell cultivation process was based on glucose consumption rate. In terms of viable cell density (VCD) and viability, cell response to the maintenance of high glucose (Table I) and L-glutamine $(4 \mathrm{mmol} / \mathrm{L})$ concentrations during cultivation process was different among the phases of cell growth (Fig. 1). During the exponential phase, VCD in all experiments that were conducted showed no statistical difference and increased on average from 0.2 to $5.3 \pm 0.3$ $\left(\times 10^{6}\right.$ cell L-1 $)$ at day 5 of cultivation. Feed additions that for all experiments were started on day 5 of cultivation and ended on day 8 (Fig. 2) took into account the measured amount of glucose $26-32 \mathrm{mmol} / \mathrm{L}$ that is by default present in the basal medium (Table II). On cultivation days 7-8 only in case of the Glucose Feed target glucose concentrations were increased higher than the plateau concentrations in order to provide excess glucose for cells if they recover in proliferation (Table I). However, on day 6 the proliferation in all feed conditions tested decreased on average to $4.6 \pm 0.3\left(\times 10^{6}\right.$ cell $\left.\mathrm{L}^{-1}\right)$ marking the end of a very short plateau phase (Fig. 1). Thus, increased glucose and glutamine concentration in none of the feeding strategies used improved the proliferation of $\mathrm{CHO}$ cell culture.

During the decline phase (days 6-12 Fig. 1), the differences caused by increased glucose and glutamine concentrations were observed. In case of Glucose Feed, a statistically significant difference of $0.7 \quad\left(\times 10^{6}\right.$ cell $\mathrm{L}^{-1}$ ) higher VCD compared to the control culture was observed (days 7-9 Fig.1). Also, irrespective of the fact that the concentration of glucose was kept at plateau level in all feeding strategies, Glucose Feed showed the highest cell viability of $91 \%$ on day 9 . On day 10 , cell viability in case of Glucose Feed was $28 \%$ higher than in case of Glutamine Control. Difference between these two feeds was only in the amount of basal medium added to the feed. On day 6, Glutamine Control experienced a statistically significant decline in VCD of $1.4\left(\times 10^{6}\right.$ cell $\mathrm{L}^{-1}$ ). On the third feeding day (day 7 of cultivation), half of the samples recovered from decline in proliferation. These observations suggest that other factors besides glucose and glutamine concentration affected cell growth and proliferation. Probably, other nutrients contained in the basal medium had an effect on cell proliferation and viability during the decline phase of cell growth. In other words, glucose and glutamine on average led to higher proliferation and viability during cell decline phase, but at the same time they were not the only factors that affected the process.

In Fig. 2 glucose concentration profiles show zigzag patterns due to the daily feed additions for all conditions tested, except the control samples. In Fig. 3 glucose consumption curves in comparison to VCD are shown. Overall, cell glucose consumption rates at various phases of growth were rather inconsistent. During the exponential phase, only in the case of Glucose Feed smooth increase in glucose consumption was observed (days 1-5 Fig. 3). Usually, increase in glucose consumption is expected at 
stationary phase [14], but due to a very short stationary phase it was not the case in the present study. During the decline phase, cells in case of the Glucose Feed experienced a decrease by $0.7\left(\mathrm{~g} \mathrm{~L}^{-1}\right)$ in glucose consumption when the feed was disrupted (day 8) which was recovered on day 9 (Fig. 3).

Overall, the decrease in cell proliferation and viability was not caused by the glucose scarcity (Fig. 2 and Fig. 3) leading to a conclusion that glucose and glutamine could not increase the proliferation when, most likely, other nutrients were depleted. Obtained results suggest that glucose and glutamine serve as the energy sources for cells, therefore, it allowed the cells to live longer, but not to proliferate. In order to improve cell proliferation, the addition of growth factors, typically peptides, small proteins and hormones, to the feed media is necessary [2].

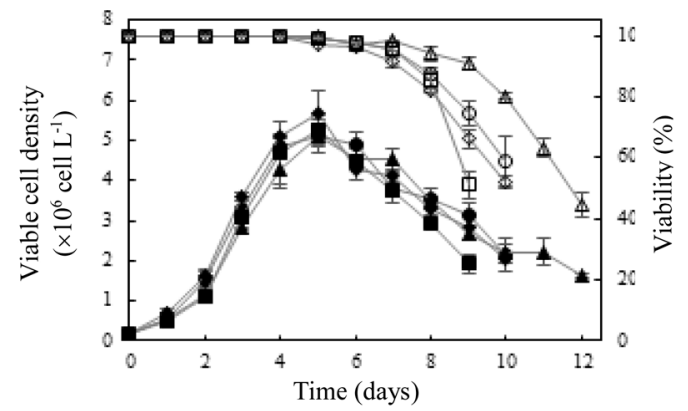

Fig. 1. Viable cell density (closed symbols) and viability (open symbols) with Glucose Control (squares), with Glucose Feed (triangles), with Glutamine Control (rhombuses), and Glutamine Feed (circles). Error bars represent one standard deviation from three biological replicates.

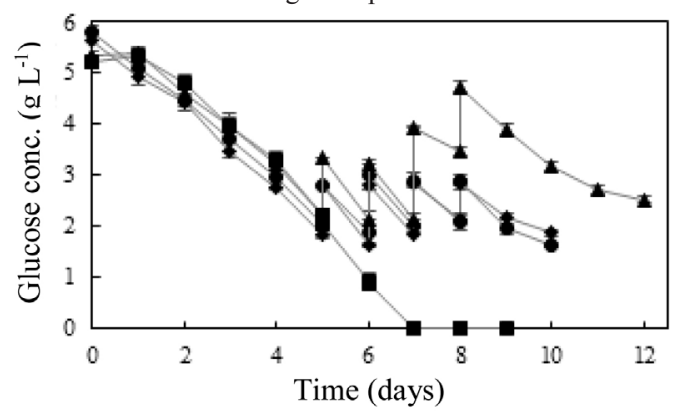

Fig. 2. Glucose concentration with Glucose Control (squares), with Glucose Feed (triangles), with Glutamine Control (rhombuses), with Glutamine Feed (circles). Error bars represent one standard deviation from three biological replicates.

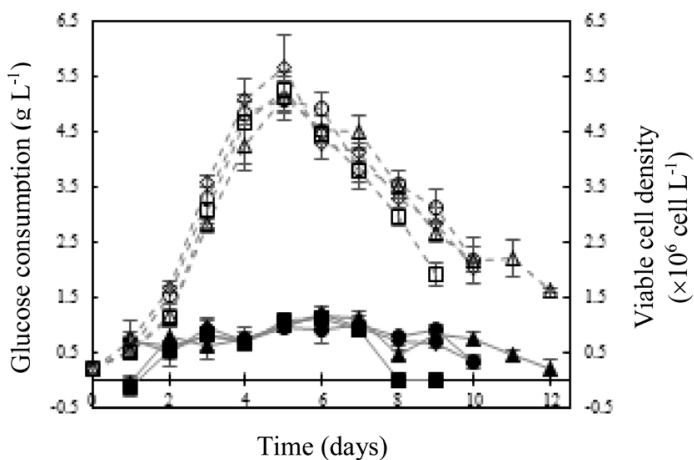

Fig. 3. Glucose consumption (closed symbols) and viable cell density (open symbols) with Glucose Control (squares), with Glucose Feed (triangles), Glutamine Control (rhombuses), with Glutamine Feed (circles). Error bars represent one standard deviation from three biological replicates.

\section{CONClusions}

In this study, cultivation process of FreeStyle ${ }^{\mathrm{TM}} \mathrm{CHO}$ high density, serum-free suspension culture cell line was characterised at increased glucose and glutamine levels maintained during the cultivation process. Obtained results suggest that increased concentration of glucose and glutamine had no statistically significant influence on $\mathrm{CHO}$ cell proliferation at exponential and plateau phases. However, cell proliferation and viability were affected during the decline phase. Results revealed statistically significant differences in viable cell density and cell viability in case of different feed media compositions when the same glucose and glutamine levels were maintained. It could be related to the preparation method of the feed media which was based on the supplementation of only two nutrients in the imbalance with other feed components in chemically defined cell culture medium.

\section{ACKNOWLEDGEMENTS}

This work has been supported by European Regional Development Fund within the project "Influence of the magnetic field initiated stirring on biotechnological processes" No. 1.1.1.1/16/A/144.

\section{REFERENCES}

[1] J. Zhu, "Mammalian cell protein expression for biopharmaceutical production," Biotechnol. Adv., vol. 30, no. 5, pp. 1158-1170, 2012.

[2] F. V. Ritacco, Y. Wu, and A. Khetan, "Cell Culture Media for Recombinant Protein Expression in Chinese Hamster Ovary (CHO) Cells: History, Key Components, and Optimization Strategies," Biotechnol Prog, vol. 34, no. 6, pp. 1407-1426, 2018.

[3] P. Xu, X. P. Dai, E. Graf, R. Martel, and R. Russell, "Effects of glutamine and asparagine on recombinant antibody production using CHO-GS cell lines," Biotechnol. Prog., vol. 30, no. 6, pp. $1457-1468,2014$.

[4] J. A. H. Bort, B. Stern, and N. Borth, "CHO-K1 host cells adapted to growth in glutamine-free medium by FACS-assisted evolution," Biotechnol. J., vol. 5, no. 10, pp. 1090-1097, 2010.

[5] L. E. Quek, S. Dietmair, J. O. Krömer, and L. K. Nielsen, "Metabolic flux analysis in mammalian cell culture," Metab. Eng., vol. 12 , no. 2 , pp. $161-171,2010$.

[6] C. A. Wilkens, C. Altamirano, and Z. P. Gerdtzen, "Comparative metabolic analysis of lactate for CHO cells in glucose and galactose," Biotechnol. Bioprocess Eng., vol. 16, no. 4, pp. 714 724, 2011.

[7] S. Lu, X. Sun, and Y. Zhang "Insight into metabolism of $\mathrm{CHO}$ cells at low glucose concentration on the basis of the determination of intracellular metabolites," Process Biochem., vol. 40, no. 5, pp. 1917-1921, 2005.

[8] P. Chen and S. W. Harcum, "Effects of amino acid additions on ammonium stressed CHO cells," J. Biotechnol., vol. 117, no. 3, pp. 277-286, 2005

[9] A. P Zeng and W. D Deckwer, "Mathematical modeling and analysis of glucose and glutamine utilization and regulation in cultures of continuous mammalian cells," Biotechnol. Bioeng., vol. 47, no. 3, pp. 334-346, 1995.

[10] H. Wlaschin, Katie F., Wei-Shou, "Fedbatch Culture and Dynamic Nutrient Feeding," Adv. Biochem. Eng. Biotechnol., vol. 101, pp. 43-74, 2006

[11] J. Robitaille, J. Chen, and M. Jolicoeur, "A single dynamic metabolic model can describe mAb producing $\mathrm{CHO}$ cell batch and fed-batch cultures on different culture media," PLoS One, vol. 10, no. 9, 2015.

[12] A. R. Costa, M. E. Rodrigues, M. Henriques, R. Oliveira, and J. Azeredo, "Feed optimization in fed-batch culture," Methods Mol. Biol., vol. 1104, pp. 105-116, 2014.

[13] X. Sun and Y. Zhang, "Glutamine cannot support recombinant $\mathrm{CHO}$ cell growth and maintenance in the absence of glucose," Process Biochem., vol. 39, no. 6, pp. 717-720, 2004.

[14] X. Pan, M. Streefland, C. Dalm, R. H. Wijffels, and D. E. Martens, "Selection of chemically defined media for CHO cell fed-batch culture processes," Cytotechnology, vol. 69, no. 1, pp. 39-56, 2017.

[15] E. Pacis, N. Vijayasankaran, J. Li, M. Gawlitzek, A. Amanullah, and F. Li, "Systematic approaches to develop chemically defined cell culture feed media," BioPharm Int., vol. 23, no. 11, pp. 22-32, 2010 . 